\title{
Isolation and characterization of proliferative, migratory and multidrug-resistant endometrial carcinoma-initiating cells from human type II endometrial carcinoma cell lines
}

\author{
YONGTAO GAO $^{1}$, TE LIU ${ }^{1,2}$, WEIWEI CHENG ${ }^{1}$ and HUI WANG ${ }^{1}$ \\ ${ }^{1}$ International Peace Maternity and Child Health Hospital, Shanghai Jiaotong University, Shanghai 200030; \\ ${ }^{2}$ Shanghai Geriatric Institute of Chinese Medicine, Shanghai 200031, P.R. China
}

Received January 30, 2012; Accepted April 3, 2012

DOI: $10.3892 /$ or.2012.1807

\begin{abstract}
Although the highly proliferative, migratory and multidrug resistant phenotype of human type II endometrial carcinoma (EC) is well characterized, improved clinical treatments have not yet been developed. In this study, CD44 and CD133 were used as markers to screen, isolate and enrich carcinoma-initiating cells (CICs) from the human type II EC cell lines KLE and ANCA3. Using flow cytometry, we identified a subpopulation of KLE and ANCA3 cells which express high levels of both CD44 and CD133 on the cell membrane. $\mathrm{CD} 44^{+} / \mathrm{CD} 33^{+} \mathrm{EC}-\mathrm{CICs}$ exhibited high levels of stemness marker genes, and possessed a higher migratory and invasive ability than CD44\%CD133- endometrial carcinoma cells (EC-CCs). CD $44^{+} / \mathrm{CD} 133^{+} \mathrm{EC}-\mathrm{CIC}$ were also more resistant to growth inhibition induced by the chemotherapeutic drugs cisplatin and paclitaxel. Additionally, CD $44^{+} / \mathrm{CD} 133^{+} \mathrm{EC}-\mathrm{CICs}$ readily established tumors in vivo in a relatively short time. In conclusion, $\mathrm{CD} 44^{+} / \mathrm{CD} 133^{+}$cells possessing the characteristics of CICs can be reliably sorted from KLE and ANCA3 human type II EC cell lines, and represent a valuable model for studying cancer cell physiology and multidrug resistance. Further characterization of CD $44^{+} / \mathrm{CD} 133^{+} \mathrm{KLE}$ and ANCA3 cells may have a profound impact on the selection of individual treatment strategies, clinical outcomes and design of the next generation of chemotherapeutic agents for type II EC.
\end{abstract}

\section{Introduction}

Type II endometrial carcinoma (EC) is one of the most common gynecologic malignancies and is usually estrogen receptor (ER) negative, poorly differentiated and high grade, with a poor

Correspondence to: Professor Yongtao Gao and Dr Te Liu, International Peace Maternity and Child Health Hospital, Shanghai Jiaotong University, Shanghai 200030, P.R. China

E-mail:enidou@yahoo.com.cn

E-mail: liute79@yahoo.com

Key words: type II endometrial carcinoma, cancer-initiating cells, CD44, CD133, proliferation, migration, invasion, multi-drug resistance prognosis (1-3). Although great progress has made in the development of therapies for type II EC, the current 5-year survival rate remains $<15 \%$, and the molecular mechanisms regulating the development and progression of type II EC are not fully understood. The most important causes of treatment failure in type II EC are metastasis, recurrence and the development of chemotherapy resistance (1); however, these mechanisms are poorly characterized.

Tumors consist of heterogeneous cell populations with different biological properties, and recent evidence suggests that the capacity for tumor formation and growth resides exclusively within a small proportion of tumor cells, termed carcinoma-initiating cells (CICs) (4-7). CICs were first isolated from acute myeloid leukemia, in which they express the cell-surface antigen CD34, but not CD38 $(8,9)$. CICs have also been isolated from primary tumors and cell lines using flow cytometry on the basis of cell-surface antigen expression (8,10-22). For instance, the CIC population is defined as $\mathrm{CD}_{133}{ }^{+}$in brain (18), melanoma (20) and lung tumors (21); $\mathrm{CD} 34^{+}$or EpCAMhigh/+/CD $44^{+} / \mathrm{CD} 166^{+}$in colon cancer (10-12); CD44 ${ }^{+}$CD24low/-/lineage- in breast tumors $(10,14)$ and $\mathrm{CD}_{4} 4^{+} / \mathrm{CD} 133^{+}$in ovarian tumors $(8,12,13)$. The observation that stem cells and some CICs share the common defining features of an incompletely differentiated state and the capacity for self-renewal has led to the cancer stem cell hypothesis, which suggests that the proliferation of a small sub-population of cells is responsible for the total tumor growth $(5-7,15)$.

Currently, clinical pathology characterizes type II EC as consisting mostly of serous and clear cell carcinomas, which typically arise in the atrophic endometrium via a mechanism unrelated to estrogen exposure (1). However, CICs have not yet been isolated from type II EC. In this study, we aimed to sort sub-populations of CICs from human type II EC cell lines, termed EC-CICs, with rates of high proliferation, migration and multi-drug resistance. Consistent with previous reports (4-22), we sorted a subpopulation of cells overexpressing CD44 and CD133 at the cell surface $\left(\mathrm{CD} 44^{+} / \mathrm{CD} 133^{+}\right)$from the ER-negative human type II EC cell lines, KLE and AN3CA, using magnetic microbeads and flow cytometry. We demonstrated that a subpopulation of CD $44^{+} / \mathrm{CD} 133^{+}$EC-CICs, which proliferate rapidly and exhibit multi-drug resistance, exist in KLE and AN3CA cells. Therefore, EC-CICs represent 
a potentially powerful in vitro model to study metastasis, invasion and the self-renewal of cancer cells, and to assess the effectiveness of novel therapeutics for type II EC.

\section{Materials and methods}

Isolation and in vitro expansion of CD44 and CD133 phenotype cells by magnetic-activated cell sorting system. CD44 and $\mathrm{CD}_{133^{+}}$subpopulation cells were isolated from human type II endometrial carcinoma cell line KLE and AN3CA using $4 \mu \mathrm{l}$ of the primary monoclonal antibodies (mouse anti-human CD133-FITC, rabbit anti-human CD44-PE, eBioscience) stored at $4^{\circ} \mathrm{C}$ in $\mathrm{PBS}$ for $30 \mathrm{~min}$ in a volume of $1 \mathrm{ml}$ as previously described $(3,8,11,22)$. After reaction, the cells were washed twice in PBS, and the secondary monoclonal antibodies (goat anti-mouse or goat anti-rabbit coupled to magnetic microbeads; Miltenyi Biotec, Auburn, CA) added, incubated at $10^{\circ} \mathrm{C}$ in PBS for $15 \mathrm{~min}$ and then washed twice in PBS. Single cells were plated at 1000 cells/ml in DMEM: F12 (HyClone), supplemented with $10 \mathrm{ng} / \mathrm{ml}$ basic fibroblast growth factor (bFGF), $10 \mathrm{ng} / \mathrm{ml}$ epidermal growth factor (EGF), $5 \mu \mathrm{g} / \mathrm{ml}$ insulin and $0.5 \%$ bovine serum albumin (BSA) (all from Sigma-Aldrich). The $\mathrm{CD} 44^{+} / \mathrm{CD} 133^{+}$cells were cultured in above conditions as non-adherent spherical clusters, EC-CICs, and CD44/CD133 cells in KLE or ANCA3 which was cultured under general conditions as adherent clusters, EC-CCs. Cells were cultured on the same conditions until passage 4 before carrying out the experiments.

Quantitative real-time PCR analysis of stem cell marker expression. Total RNA from the cells was isolated using TRIzol reagent (Invitrogen) according to the manufacturer's protocol. The RNA samples were treated with Dnase I (SigmaAldrich), quantified, and reverse-transcribed into cDNA using the ReverTra Ace- $\alpha$ First Strand cDNA Synthesis kit (Toyobo). Quantitative real-time PCR (qRT-PCR) was conducted using a RealPlex4 real-time PCR detection system from Eppendorf Co., Ltd. (Germany), with SyBR Green real-time PCR Master MIX (Toyobo) used as the detection dye. qRT-PCR amplification was performed over 40 cycles with denaturation at $95^{\circ} \mathrm{C}$ for $15 \mathrm{sec}$ and annealing at $58^{\circ} \mathrm{C}$ for $45 \mathrm{sec}$. Target cDNA was quantified using the relative quantification method. A comparative threshold cycle $(\mathrm{Ct})$ was used to determine gene expression relative to a control (calibrator) and steady-state mRNA levels are reported as an $n$-fold difference relative to the calibrator. For each sample, the gene $\mathrm{Ct}$ value was normalized using the formula $\Delta \mathrm{Ct}=\mathrm{Ct}_{\text {markers }}-\mathrm{Ct}_{18 \mathrm{~s} \text { rRNA}}$. To determine relative expression levels, the following formula was used $\Delta \Delta \mathrm{Ct}=\Delta \mathrm{Ct}_{\mathrm{CICs}}$ $-\Delta \mathrm{Ct}_{\mathrm{CCs}}$. The values to plot relative expressions of markers were calculated using the expression $2^{-\Delta \Delta \mathrm{Ct}}$. The mRNA levels were calibrated based on levels of $18 \mathrm{~s}$ rRNA. The cDNA of each stem cell markers was amplified using primers as previously described (11).

Multi-chemodrugs resistant assay. The chemodrugs (cisplatin, paclitaxel, adriamycin and methotrexate) resistant assay of the cells was performed as previously described (11).

Western blot analysis. Protein extracts of the cell were resolved by $12 \%$ SDS-PAGE and transferred on PVDF (Millipore) membranes. After blocking, the PVDF membranes were washed 4 times for 15 min with TBST at room temperature and incubated with primary antibody (rabbit anti-human CD133, rabbit anti-human CD44, all from Santa Cruz Biotechnology). Following extensive washing, membranes were incubated with secondary peroxidase-linked goat anti-rabbit IgG (Santa Cruz Biotechnology) for $1 \mathrm{~h}$. After washing 4 times for $15 \mathrm{~min}$ with TBST at room temperature once more, the immunoreactivity was visualized by enhanced chemiluminescence (ECL kit, Pierce Biotechnology).

Immunofluorescence staining analysis of relative protein expression. The cultured cells were washed 3 times with FCS and fixed with $4 \%$ paraformaldehyde (Sigma-Aldrich, St. Louis, MO, USA) for $30 \mathrm{~min}$. After blocking, the cells were incubated first with rabbit anti-human Oct3/4 polyclonal antibody (1:200; Chemicon, Temecula, CA, USA) and rabbit anti-human Nanog polyclonal antibody (1:200; Chemicon, Temecula) overnight at $4^{\circ} \mathrm{C}$, and then with FITC-conjugated goat anti-rabbit IgG antibody (1:200; Abcam, Cambridge, UK) and $5 \mu \mathrm{g} / \mathrm{ml}$ DAPI (Sigma-Aldrich) at room temperature for $30 \mathrm{~min}$. Then the cells were thoroughly washed with TBST and viewed through a fluorescence microscope (DMI3000; Leica, Allendale, NJ, USA).

Soft agar colony formation assay. All the steps were as previously described $(2,23)$. Soft Agar Assays were constructed in 6-well plates. The base layer of each well consisted of $2 \mathrm{ml}$ with final concentrations of $1 \mathrm{X}$ media (DMEM+10\% FBS) and $0.6 \%$ low melting point agarose. Plates were chilled at $4{ }^{\circ} \mathrm{C}$ until solid. Upon this, a 1.0-ml growth agar layer was poured, consisting of $1 \times 10^{4}$ cells suspended in $1 \mathrm{X}$ media and $0.3 \%$ low melting point agarose. Plates were again chilled at $4^{\circ} \mathrm{C}$ until the growth layer congealed. An additional $1.0 \mathrm{ml}$ of $1 \mathrm{X}$ media without agarose was added on top of the growth layer on Day 0 and again on Day 15 of growth. Cells were allowed to grow at $37^{\circ} \mathrm{C}$ for 1 month and total colonies counted. Assays were repeated a total of 3 times. Results were statistically analyzed by paired t-test using the PRISM Graphpad program.

Transwell migration assay. All the steps were as previously described $(2,23)$. Cells $\left(2 \times 10^{5}\right)$ were resuspended in $200 \mu 1$ of serum-free medium and seeded on the top chamber of the $8.0-\mu \mathrm{m}$ pore, $6.5 \mathrm{~mm}$ polycarbonate transwell filters (Corning). The full medium $(600 \mu \mathrm{l})$ containing $10 \%$ FBS was added to the bottom chamber. The cells were allowed to migrate for $24 \mathrm{~h}$ at $37^{\circ} \mathrm{C}$ in a humidified incubator with $5 \% \mathrm{CO}_{2}$. The cells attached to the lower surface of membrane were fixed in $4 \%$ paraformaldehyde at room temperature for $30 \mathrm{~min}$ and stained with 4,6-diamidino-2-phenylindole (DAPI) (C1002, Beyotime Institute of Biotechnology, China), and the number of cells on the lower surface of the filters was counted under the microscope. A total of 5 fields were counted for each transwell filter.

In vivo xenograft experiments. Cells $\left(6 \times 10^{5}\right)$ (EC-CICs oEC normal cell lines) were inoculated s.c. in athymic nude mice, 6-7 weeks of age. The animal studies were carried out at Tongji University with Institutional Anminal Care and Use Committer approval in accordance with institutional guidelines. 


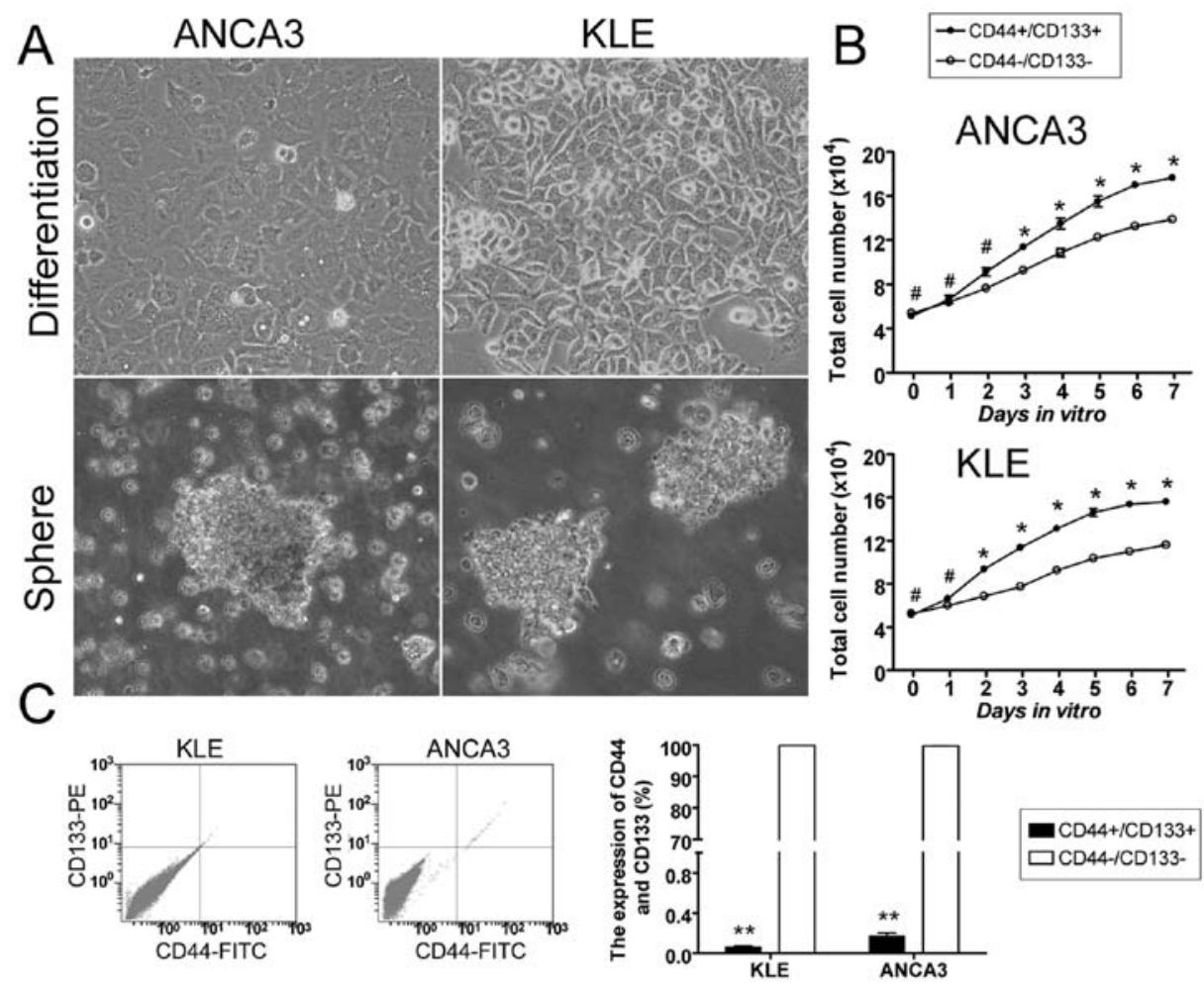

Figure 1. Isolation and characterization of $\mathrm{CD}_{4} 4^{+} / \mathrm{CD} 133^{+}$expressing EC-CICs and CD44 /CD133- EC-CCs. (A) Morphology of the CD44 $/ \mathrm{CD} 133^{+}$subpopulation from the human type II endometrial carcinoma cell lines KLE and ANCA3. After flow cytometry (FCM) sorting, CD44/CD133 EC-CCs were cultured under differentiating conditions and $\mathrm{CD} 44^{+} / \mathrm{CD} 133^{+} \mathrm{EC}-\mathrm{CICs}$ were cultured under sphere forming conditions in suspension. EC-CICs formed small, non-adherent, non-symmetrical spheres under stem cell-selective conditions. (B) Mean numbers of KLE and ANCA3 EC-CICs and EC-CCs on days 1-7 after passage. (C) Flow cytometric analysis of the number of KLE and ANCA3 cells expressing CD44 and CD133 before and after FCM sorting for CD44 and CD133; ${ }^{* *} \mathrm{p}<0.01$ and ${ }^{\#} \mathrm{p}>0.05$ vs. CD44-CD133- EC-CCs $(\mathrm{n}=3)$.

Statistical analysis. Each experiment was performed as least three times, and data are shown as the mean \pm SE where applicable, and differences were evaluated using Student's t-tests. The probability of $<0.05$ was considered to be statistically significant.

\section{Results}

To determine whether CICs exist in human type II EC cell lines, CD44 and CD133 were used as markers of CICs to isolate endometrial CICs from two human type II EC cell lines, KLE and ANCA3. Then, the stemness, proliferation, migration and multidrug resistance of $\mathrm{CD} 44^{+} / \mathrm{CD} 133^{+}$cells (EC-CICs) and CD44\% CD133- endometrial cancer cells (EC-CCs) were assayed.

Isolation and enrichment of $\mathrm{CD}_{4} 4^{+}$and $\mathrm{CD} 133^{+} \mathrm{EC}$-CICs . Previous studies have suggested that the human $\mathrm{CD} 44^{+} /$ $\mathrm{CD}_{133^{+}} \mathrm{CIC}$ subpopulation is relatively small in many tumor types. Therefore, we used a magnetic-activated cell sorting system to isolate and enrich the CD44 and CD133 subpopulation from two type II EC cell lines. After isolation, the cells were quantified by flow cytometry (FCM). CD $44^{+} / \mathrm{CD} 133^{+}$ cells represented $0.063 \pm 0.012 \%$ and $0.177 \pm 0.024 \%$ of the total population in KLE and ANCA3 cell lines, whereas CD44\% CD133 cells represented $99.897 \pm 0.009 \%$ and $99.743 \pm 0.041 \%$ of the total population, respectively (Fig. 1). These results demonstrated that $\mathrm{CD} 44^{+} / \mathrm{CD} 133^{+}$cells, although very exiguous, could be successfully enriched from human type II EC cell lines using magnetic-activated cell sorting.
CD44 and CD133 EC-CIC proliferation. The proliferation rates of $\mathrm{EC}-\mathrm{CICs}\left(\mathrm{CD} 44^{+} / \mathrm{CD} 133^{+}\right.$cells) and EC-CCs (CD44\% CD133 cells) were examined on days 1-7 after passage. All measurements were repeated in triplicate. There was no significant difference in the number of KLE EC-CICs and EC-CCs on days 0 and 1 . However, between days 2 and 7, KLE EC-CICs divided significantly more rapidly than EC-CCs ( $<<0.05$, t-test). Similarly, there was no significant difference in the number of ANCA3 EC-CICs and EC-CCs on days 0 and 2; however, between days 3 and 7, ANCA3 EC-CICs divided significantly more rapidly than EC-CCs ( $<<0.05$, t-test).

CD $44^{+} / C D 133^{+}$EC-CICs overexpress stem cell markers. Quantitative real-time polymerase chain reaction (qRT-PCR) was used to compare the relative gene expression levels of several stem cell markers in EC-CICs and EC-CCs, using 18s rRNA as an internal control. The expression of Nanog, Oct4, Sox2, Tert, ABCG2, CD44, CD133 and CD117 were all significantly higher in EC-CICs than EC-CICs ( $p<0.05$; Fig. 2). Immunofluorescence staining (IF) confirmed that $\mathrm{CD} 44^{+} /$ $\mathrm{CD}_{133^{+}}$EC-CICs expressed higher levels of the stem cell markers Nanog and Oct4 than EC-CCs (Fig. 2). These results suggested that both KLE and ANCA3 EC-CICs possess stem cell characteristics.

Additionally, expression of CD44 and CD133 were evaluated in KLE and ANCA3 EC-CICs and EC-CCs using western blot analysis. In EC-CICs, the levels of CD44 and CD133 were $0.586 \pm 0.051 \%$ and $0.415 \pm 0.008 \%$ of KLE and 

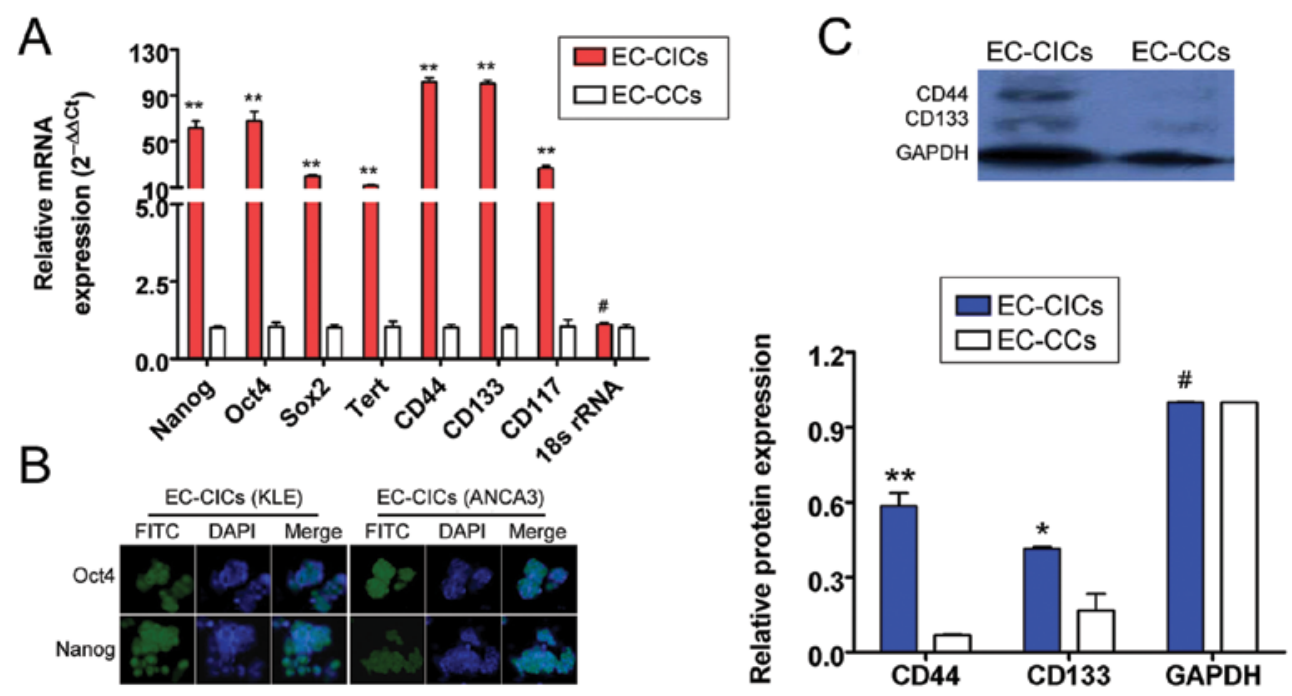

Figure 2. Expression of stem cell markers is increased in $\mathrm{CD}_{4} 4^{+} / \mathrm{CD} 133^{+} \mathrm{EC}-\mathrm{CICs}$ compared to CD44/CD133- EC-CCs. (A) qRT-PCR analysis of the relative expression levels of stem cell marker genes in EC-CICs and EC-CCs; ${ }^{* *} \mathrm{p}<0.01$ and ${ }^{*} \mathrm{p}>0.05$ vs. EC-CCs $(\mathrm{n}=3)$. (B) Immunofluorescent staining of the stem cell markers Nanog and Oct4 in EC-CICs and EC-CCs; original magnification, x200. (C) Western blot analysis of CD44 and CD117 protein expression in EC-CICs and EC-CCs; ${ }^{* *} \mathrm{p}<0.01,{ }^{*} \mathrm{p}<0.05$ and ${ }^{\#} \mathrm{p}>0.05$ vs. EC-CCs $(\mathrm{n}=3)$.
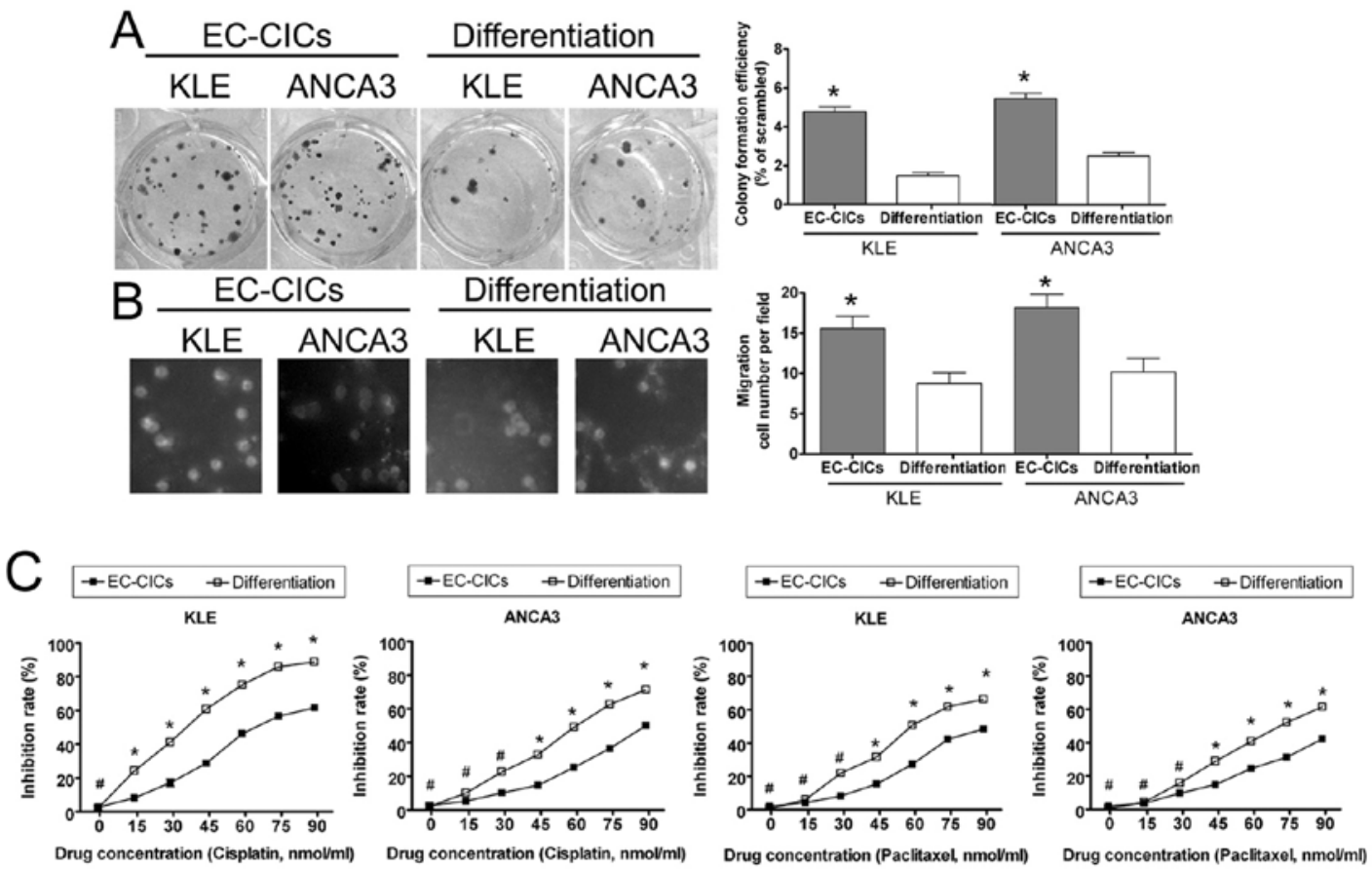

Figure 3. $\mathrm{CD}_{4} 4^{+} / \mathrm{CD} 133^{+} \mathrm{EC}-\mathrm{CICs}$ have higher migratory and invasive ability and increased multi-drug resistance compared to $\mathrm{CD} 44^{-} / \mathrm{CD} 133^{-} \mathrm{EC}-\mathrm{CCs}$. (A) Soft agar colony formation assays of EC-CICs and EC-CCs plated at low density. (B) Transwell migration invasion assays of EC-CICs and EC-CCs. (C) MTT assays of the effect of cisplatin and paclitaxel on EC-CICs and differentiated EC-CCs. Cell inhibition is calculated relative to untreated CD44 $/ \mathrm{CD}^{+} 33^{+}$ EC-CICs or EC-CCs; ${ }^{* *} \mathrm{p}<0.01,{ }^{*} \mathrm{p}<0.05$ and ${ }^{*} \mathrm{p}>0.05$ vs. differentiated EC-CCs $(\mathrm{n}=3)$.

ANCA3, respectively (Fig. 2). These values were significantly higher than CD44 and CD133 in EC-CCs $(0.068 \pm 0.003$ and $0.168 \pm 0.068$ of KLE and ANCA3, respectively). These results confirmed that both CD44 and CD133 are expressed at high levels in EC-CICs.

$C D 44^{+} / C D 133^{+}$EC-CICs have increased migratory and invasive ability. The ability of EC-CICs and EC-CCs to migrate and invade were determined using the transwell migration assay and soft agar colony formation assay, respectively. The transwell migration invasion assay showed that significantly fewer EC-CCs invaded, compared to EC-CICs (invading cell numbers: KLE EC-CICs $16 \pm 2$ vs. EC-CCs $9 \pm 1$, p $<0.05$; ANCA3 EC-CICs $18 \pm 2$ vs. EC-CCs $10 \pm 2$, p<0.05; Fig. 3 ). Moreover, the soft agar colony formation assay indicated that EC-CCs formed substantially fewer colonies when plated at 
A

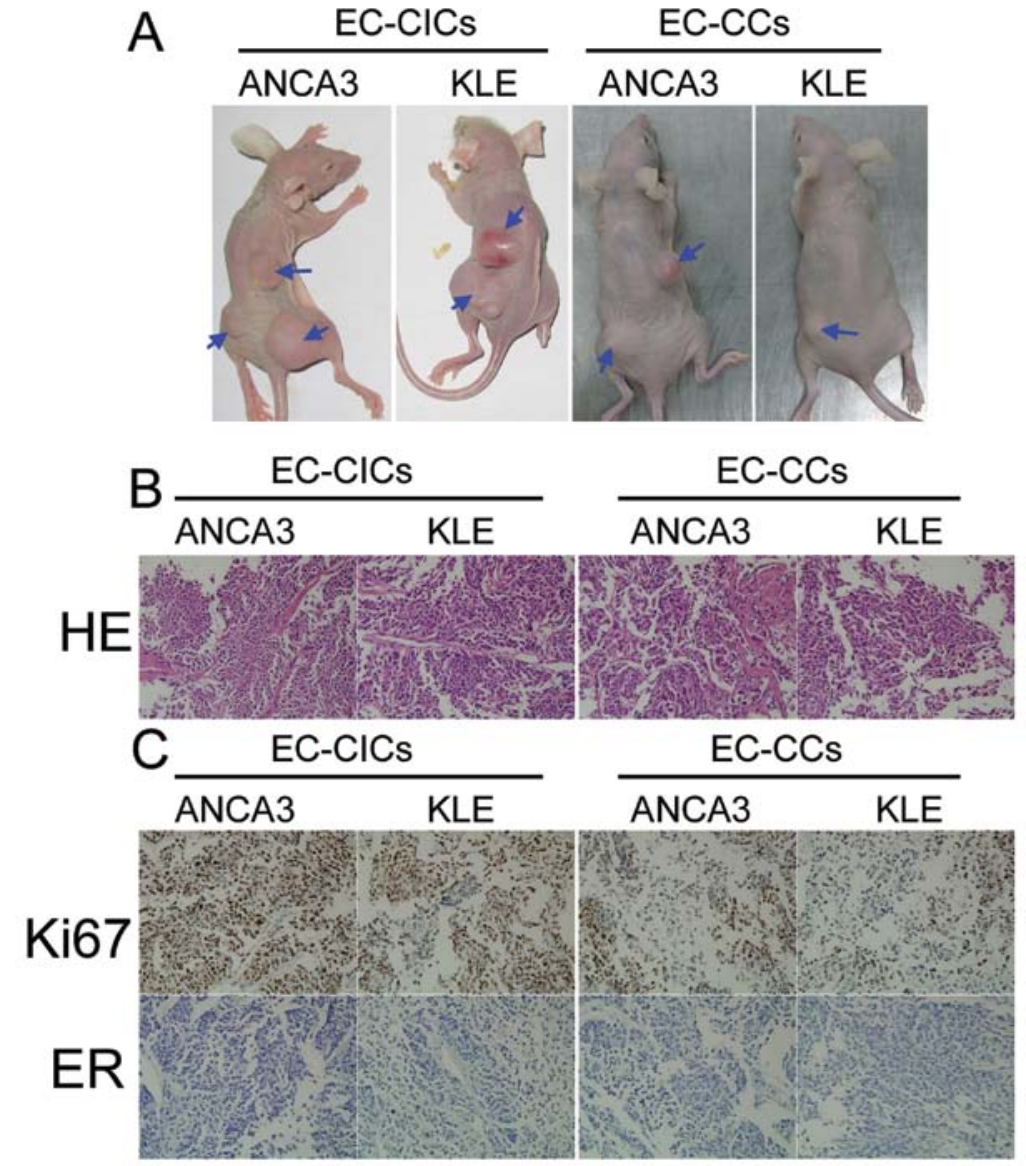

EC-CCs

Figure $4 . \mathrm{CD}_{4} 4^{+} / \mathrm{CD} 133^{+}$EC-CICs have increased in vivo tumor formation ability compared to CD44/CD133- EC-CCs. CD44 $/ \mathrm{CD} 133^{+} \mathrm{EC}-\mathrm{CICs}$ or $\mathrm{CD} 44^{-} /$ CD133 EC-CCs were subcutaneously inoculated into SCID mice to form in vivo xenografts. (A) Representative images of the xenograft tumors, blue arrows indicate the tumor tissues 68 days after injection. (B) Hematoxylin and eosin (HE) staining of EC-CICs and EC-CCs tumors, revealing the cellular heterogeneity of the tumors. Original magnification, x200. (C) Immunohistochemical staining of the cell proliferation marker Ki-67 and estrogen receptor (ER), indicating weakly positive staining in EC-CIC tumors and positive or strongly positive staining in EC-CC tumors. Moreover, not all cells in the CD44 $/ \mathrm{CD} 133^{+}$ EC-CICs or CD44-CD133- EC-CCs group expressed estrogen receptor (ER-negative). Original magnification, x200.

low density than EC-CICs (colony formation efficiency: KLE EC-CCs $1.48 \pm 0.16 \%$ vs. EC-CICs $4.78 \pm 0.25 \%$, p<0.05; ANCA3 EC-CCs $2.52 \pm 0.18 \%$ vs. EC-CICs $5.48 \pm 0.29 \%$, p<0.05; Fig. 3).

CD $44^{+} / C D 133^{+}$EC-CICs exhibit multi-drug resistance. In order to evaluate the multi-drug resistance of EC-CICs and EC-CCs, the inhibitory rates of cisplatin and paclitaxel $(0,15$, $30,45,60,75$ and $90 \mathrm{nmol} / \mathrm{ml}$ ) were measured using the MTT proliferation assay. The growth of both EC-CICs and EC-CCs were inhibited by cisplatin and paclitaxel; however, EC-CICs were significantly less susceptible to the cytotoxic effects of the drugs (Fig. 3). Thus, CD $44^{+} / \mathrm{CD} 133^{+}$EC-CICs were more resistant to cisplatin and paclitaxel than $\mathrm{CD} 44^{-/ C D} 133$ EC-CCs, suggesting that the $\mathrm{CD} 44^{+} / \mathrm{CD} 133^{+}$subpopulation may be resistant to a broad spectrum of chemotherapeutics.

The $\mathrm{CD} 44^{+} / \mathrm{CD} 133^{+}$subpopulation of EC-CICs induces tumor growth in vivo. In order to evaluate the tumorigenic capacity of EC-CICs and EC-CCs, 7x10 4 EC-CICs or EC-CCs were subcutaneously inoculated into athymic nude mice. Tumors were visible in the EC-CIC-injected mice after 68 days; however, EC-CC-injected mice did not have detectable tumors at this time (Fig. 4). Very small tumors were detected in EC-CC-injected mice after 94 days. When the mice were sacrificed 110 days after injection, the tumors formed by EC-CICs were significantly heavier than the tumors formed by EC-CCs. As tumor growth is determined by the balance of cell proliferation and programmed cell death, the cell proliferation-related protein Ki-67 was analyzed in the tumor sections using immunohistochemistry. The tumors formed by EC-CICs displayed positive or strongly positive $\mathrm{Ki}-67$ staining, while the tumors formed by EC-CCs exhibited only weak Ki-67 immunoreactivity (Fig. 4). Moreover, HE staining revealed cellular heterogeneity in both the EC-CIC and EC-CC tumors. Taken together, the in vivo xenograft model indicated that low numbers of CD $44^{+} / \mathrm{CD} 133^{+}$ EC-CICs have the potential to initiate tumor growth.

\section{Discussion}

Increasing numbers of studies have indicated the presence of cancer-initiating cells (CICs, also known as cancer stem cells) in most tumor types. CICs are thought to play an important role in the recurrence, metastasis and multi-drug resistance of cancer. CICs have several prominent characteristics, including clonogenicity, the ability to self-renew and differentiate in vitro to form organized spheroids in suspension, and the expression 
of multipotency and tissue-specific differentiation markers. CICs can also generate tumors in vivo through self-renewal mechanisms, and undergo differentiation in vivo to produce diseases similar to those in human patients (11). Additionally, the stem cell marker receptor, CD117 (also known as c-kit), is expressed in various CICs, as well as by stem cells and hematopoietic progenitor cells. However, CICs from human endometrial carcinoma, especially type II EC, have not previously been isolated. There is ample evidence to demonstrate the importance of CD44 expression during the progression of many tumor types, and CD44, a glycoprotein receptor which binds hyaluronan, is expressed by many CICs (24). CD44 is encoded by a single gene and varies in size due to alternative splicing of the extracellular domains and $\mathrm{N}$-glycosylation or O-glycosylation (24). In this study, CD44 and the crucial stem cell marker CD133 were used as markers to screen, isolate and enrich CICs from human type II EC cell lines.

We identified a subpopulation of cells which express high levels of both CD44 and CD133 on the cell membrane in the human type II EC cell lines KLE and ANCA3. The CD $44^{+} / \mathrm{CD} 133^{+}$subpopulation overexpressed several stem cell markers, including Nanog, Oct4, Sox2, Tert and CD177. $\mathrm{CD} 44^{+} / \mathrm{CD} 133^{+}$cells proliferated at a higher rate, and the transwell migration assay and soft agar colony formation assay demonstrated that the $\mathrm{CD} 44^{+} / \mathrm{CD} 133^{+}$subpopulation had a increased migratory and invasive ability, compared to CD44\% CD133- cells. Additionally, the $\mathrm{CD} 44^{+} / \mathrm{CD} 133^{+}$subpopulation was more resistant to the chemotherapeutic agents, cisplatin and paclitaxel, and readily and rapidly formed xenografts in vivo from extremely small numbers of cells. As the CD $44^{+} /$ $\mathrm{CD}_{133^{+}}$subpopulation exhibited the classical characteristics of stem cells, we suggest that the $\mathrm{CD} 44^{+} / \mathrm{CD} 133^{+}$subpopulation are endometrial carcinoma-initiating cells (EC-CICs). Moreover, as EC-CICs possess common stem cell characteristics and exhibit multi-drug resistance, these cells may serve as an experimental platform to both study tumor cell physiology and examine the effectiveness of clinical therapeutics for type II EC.

In conclusion, CD44 and CD133 can be used to isolate a subpopulation of cells from human type II EC cell lines. The $\mathrm{CD} 44^{+} / \mathrm{CD} 133^{+} \mathrm{EC}$ subpopulation displays the proliferative, migratory, stem-cell and multi-drug resistance characteristics of CICs, and may provide an important model for future studies of therapeutic strategies in type II EC.

\section{Acknowledgements}

This study was supported by grant from Shanghai Municipal Health Bureau Fund (No. 2010260) to Y.G.

\section{References}

1. Gehrig PA and Bae-Jump VL: Promising novel therapies for the treatment of endometrial cancer. Gynecol Oncol 116: 187-194, 2010 .
2. Jiang F, Liu T, He Y, et al: MiR-125b promotes proliferation and migration of type II endometrial carcinoma cells through targeting TP53INP1 tumor suppressor in vitro and in vivo. BMC Cancer 11: 425, 2011.

3. Bokhman JV: Two pathogenetic types of endometrial carcinoma. Gynecol Oncol 15: 10-17, 1983.

4. Ponti D, Costa A, Zaffaroni N, et al: Isolation and in vitro propagation of tumorigenic breast cancer cells with stem/progenitor cell properties. Cancer Res 65: 5506-5511, 2005.

5. Reya T, Morrison SJ, Clarke MF and Weissman IL: Stem cells, cancer, and cancer stem cells. Nature 414: 105-111, 2001.

6. Marx J: Cancer research. Mutant stem cells may seed cancer. Science 301: 1308-1310, 2003.

7. Pardal R, Clarke MF and Morrison SJ: Applying the principles of stem-cell biology to cancer. Nat Rev Cancer 3: 895-902, 2003.

8. Zhang S, Balch C, Chan MW, et al: Identification and characterization of ovarian cancer-initiating cells from primary human tumors. Cancer Res 68: 4311-4320, 2008.

9. Bonnet D and Dick JE: Human acute myeloid leukemia is organized as a hierarchy that originates from a primitive hematopoietic cell. Nat Med 3: 730-737, 1997.

10. Mayol JF, Loeuillet C, Herodin F and Wion D: Characterisation of normal and cancer stem cells: one experimental paradigm for two kinds of stem cells. Bioessays 31: 993-1001, 2009.

11. Liu T, Xu F, Du X, et al: Establishment and characterization of multi-drug resistant, prostate carcinoma-initiating stem-like cells from human prostate cancer cell lines 22RV1. Mol Cell Biochem 340: 265-273, 2010.

12. Ma L, Lai D, Liu T, Cheng W and Guo L: Cancer stem-like cells can be isolated with drug selection in human ovarian cancer cell line SKOV3. Acta Biochim Biophys Sin (Shanghai) 42: 593-602, 2010.

13. Liu T, Cheng W, Lai D, Huang Y and Guo L: Characterization of primary ovarian cancer cells in different culture systems. Oncol Rep 23: 1277-1284, 2010.

14. Al-Hajj M, Wicha MS, Benito-Hernandez A, Morrison SJ and Clarke MF: Prospective identification of tumorigenic breast cancer cells. Proc Natl Acad Sci USA 100: 3983-3988, 2003.

15. Dalerba P, Dylla SJ, Park IK, et al: Phenotypic characterization of human colorectal cancer stem cells. Proc Natl Acad Sci USA 104: 10158-10163, 2007.

16. O'Brien CA, Pollett A, Gallinger S and Dick JE: A human colon cancer cell capable of initiating tumour growth in immunodeficient mice. Nature 445: 106-110, 2007.

17. Ricci-Vitiani L, Lombardi DG, Pilozzi E, et al: Identification and expansion of human colon-cancer-initiating cells. Nature 445: 111-115, 2007.

18. Singh SK, Hawkins C, Clarke ID, et al: Identification of human brain tumour initiating cells. Nature 432: 396-401, 2004.

19. Lapidot T, Sirard C, Vormoor J, et al: A cell initiating human acute myeloid leukaemia after transplantation into SCID mice. Nature 367: 645-648, 1994.

20. Monzani E, Facchetti F, Galmozzi E, et al: Melanoma contains CD133 and ABCG2 positive cells with enhanced tumourigenic potential. Eur J Cancer 43: 935-946, 2007.

21. Eramo A, Lotti F, Sette G, et al: Identification and expansion of the tumorigenic lung cancer stem cell population. Cell Death Differ 15: 504-514, 2008.

22. Dou J, Pan M, Wen P, et al: Isolation and identification of cancer stem-like cells from murine melanoma cell lines. Cell Mol Immunol 4: 467-472, 2007.

23. Gupta RA, Shah N, Wang KC, et al: Long non-coding RNA HOTAIR reprograms chromatin state to promote cancer metastasis. Nature 464: 1071-1076, 2010.

24. Zöller M: CD44: can a cancer-initiating cell profit from an abundantly expressed molecule? Nat Rev Cancer 11: 254-267, 2011. 